\title{
AUTOMATIC WAREHOUSES WITH TRANSPORT ROBOTS OF INCREASED RELIABILITY
}

\author{
Sergey Trefilov \\ 7 Studencheskaya St., Izhevsk, 426069, Udmurt republic, Russian Federation, Kalashnikov Izhevsk State Technical \\ University, trefilov376908@gmail.com

\section{Yury Nikitin} \\ 7 Studencheskaya St., Izhevsk, 426069, Udmurt republic, Russian Federation, Kalashnikov Izhevsk State Technical
} University, nikitin@istu.ru (corresponding author)

Keywords: warehouses, robots, control, diagnostics

Abstract: The algorithm of optimal control of transport robots for automatic warehouses is considered in the paper. The minimum criterion for a quadratic form was chosen as the criterion of optimality. A quadratic functional of quality that determines the energy of control and displacement is considered. A solution is proposed for a quality criterion that minimizes the energy of control and displacement. The robots control based on a mathematical model is proposed with the calculation of the state matrices and the control matrix at each step. The properties of transport robots system are considered: controllability and identifiability. For a linear stationary system, the criteria for controllability, identifiability and observability as the rank of the extended matrix are chosen. It is proposed to perform diagnostics of drives, electronic control devices and software in a complex manner based on the parametric model and calculation of the identifiability criterion. A large inaccuracy in the measurement results in a larger control error and a loss of controllability. Moreover, with the loss of identifiability, the measurement problem becomes poorly conditioned. This approach will allow to perform complex diagnostics of transport robots system and in time to identify potentially faulty components and exclude them from the system.

\section{Introduction}

There are many papers on automatic warehouses and transportation equipment [1-7]. The development of wheeled vehicles of general and special purpose is considered in papers [8-11]. In papers [12-18] problems of diagnostics of transport robots and their drives are considered.

At present, much attention is paid to the reliability and safety of the use of complex systems, which include multiagent automatic warehouse systems. As a rule, the model of technical systems reliability is represented in the form of a connection between the failure rate parameter and the probability of failure. All models of system diagnostics are defined either as diagnostics of individual elements of the system in order to confirm their probabilistic model, or as a complex analysis of probabilistic models for the entire system, taking into account the connection between the elements.

The main attention is paid to the accuracy of measurements for verification of the probabilistic reliability model. The solution of diagnostic problems in practical tasks is confronted with measuring poorlydefined tasks. Moreover, the probabilistic model based on the failure rate is oriented to sudden failures, although for complex systems it is characteristic to remain operational even if some or all of the elements of this system fail. This approach implies an increase in the number of information measuring diagnostic subsystems at the element level with very complex algorithms for processing primary data and decision algorithms for reliability system.

In this paper, we propose a systematic approach to the solution of the problem of diagnostics of complex systems, based on the construction of a matrix mathematical model that assumes the possibility of computing the properties of complex systems such as controllability, observability, and identifiability. These properties are used to diagnose a complex system in the sense of its ability to perform an a priori specified objective function. The model of a complex system is represented as:

where:

$$
\begin{aligned}
& \dot{x}=A(t) x(t)+B(t) u(t) \\
& z(t)=C(t) x(t)
\end{aligned}
$$

$\mathrm{A}(\mathrm{t})$ is a functional matrix of size $\mathrm{n} \times \mathrm{n}$, called the state matrix of the system (object);

$\mathrm{B}(\mathrm{t})$ is a functional matrix of size $\mathrm{n} \times \mathrm{r}$, called the control matrix (input);

$\mathrm{C}(\mathrm{t})$ is a functional matrix of size $\mathrm{m} \times \mathrm{n}$, called the exit state matrix.

Controllability, observability and identifiability are determined by the rank of the matrix sequence 
$\operatorname{rank}\left[B_{k}: A_{k} B_{k} \vdots\left(A_{k}\right)^{2} B_{k} \vdots \cdots:\left(A_{k}\right)^{n-1} B_{k}\right]=n$, $\operatorname{rank}\left[C_{k}^{\mathrm{T}}: A_{k}^{\mathrm{T}} C_{k}^{\mathrm{T}}:\left(A_{k}^{\mathrm{T}}\right)^{2} C_{k}^{\mathrm{T}} \vdots \cdots:\left(A_{k}^{\mathrm{T}}\right)^{\mathrm{n}-1} C_{\mathrm{k}}^{\mathrm{T}}\right]=\mathrm{n}$.

\section{Methodology}

Let the automatic warehouse be serviced by $n$ highly manoeuvrable robots, each of which has three degrees of freedom, that is, the state of the robot is determined by the speed of linear displacement with respect to the coordinates $\mathrm{x}, \mathrm{y}$ and rotation around the $\mathrm{z}$ coordinate. Then the state vector can be written as

$$
x^{T}=\left[v_{x}(t), v_{y}(t), \omega(t)\right]^{T}
$$

In general, when all vectors and matrices are timedependent, the problem is non-linear and has only particular solutions. To find the equation of state, we represent (1) in a discrete form, with the sampling time $\Delta t$ tending to zero, and the trajectory on each discrete part is linear. We write (1) in the form

$$
\begin{array}{r}
\frac{x_{k+1}-x_{k}}{\Delta t}=A_{k} x_{k}+B_{k} u_{k} \\
z_{k}=C_{k} x_{k}
\end{array}
$$

This approach involves the calculation of the state matrices $\mathrm{A}(\mathrm{t})$, the control $\mathrm{B}(\mathrm{t})$, and the measurement of $\mathrm{C}(\mathrm{t})$ in the solution of the measurement task.

Multiplying the left and right sides of the first equation by $\Delta \mathrm{t}$, we obtain

$$
\begin{aligned}
& x_{k+1}=\tilde{A}_{k} x_{k}+\tilde{B}_{k} u_{k}, \\
& z_{k}=C_{k} x_{k}
\end{aligned}
$$

where $\tilde{A}=\Delta t \cdot A+E$,

$\tilde{B}=\Delta t \cdot B$.

This equation relates the transition of the system from the state $x_{k}$ to the state $x_{k+1}$. In the interval $\Delta \mathrm{t}$ we take the values of the matrices to be constant. Then for a group of highly manoeuvrable transport robots [11] having a state vector

$$
x^{T}=\left[v_{x}(t), v_{y}(t), \omega(t)\right]^{T}
$$

and driven by two drives, we can to record for the whole ensemble of $\mathrm{n}$ robots is similar to (3).

$$
\begin{aligned}
& {\left[\begin{array}{c}
v_{k+1 x}(1) \\
v_{k+1 y}(1) \\
\omega_{k+1}(1) \\
\vdots \\
v_{k+1 x}(n) \\
v_{k+1 y}(n) \\
\omega_{k+1}(n)
\end{array}\right]=\left[\begin{array}{lllll}
a_{11} & a_{12} & \ldots & a_{1(2 n-1)} & a_{1(3 n)} \\
a_{21} & a_{22} & \ldots & a_{2(2 n-1)} & a_{2(3 n)} \\
& & \ldots & & \\
a_{(3 n-1) 1} & a_{(3 n-1) 2} & \ldots & a_{(3 n-1)(2 n-1)} & a_{(3 n-1)(3 n)} \\
a_{(3 n) 1} & a_{(3 n) 2} & \ldots & a_{(3 n)(2 n-1)} & a_{(3 n)(3 n)}
\end{array}\right] \cdot\left[\begin{array}{c}
v_{k x}(1) \\
v_{k y}(1) \\
\omega_{k}(1) \\
\vdots \\
v_{k x}(n) \\
v_{k y}(n) \\
\omega_{k}(n)
\end{array}\right]+} \\
& +\left[\begin{array}{ccclc}
b_{11} & b_{12} & \ldots & b_{1(2 n-1)} & b_{1(2 n)} \\
b_{21} & b_{22} & \ldots & b_{2(2 n-1)} & b_{2(2 n)} \\
b_{(3 n-1) 1} & b_{(3 n-1) 2} & \ldots & b_{(3 n-1)(2 n-1)} & b_{(3 n-1)(2 n)} \\
b_{(3 n) 1} & b_{(3 n) 2} & \ldots & b_{(3 n)(2 n-1)} & b_{(3 n)(2 n)}
\end{array}\right]\left[\begin{array}{c}
u_{11} \\
u_{12} \\
u_{21} \\
u_{22} \\
\vdots \\
\vdots \\
u_{n 1} \\
u_{n 2}
\end{array}\right]
\end{aligned}
$$

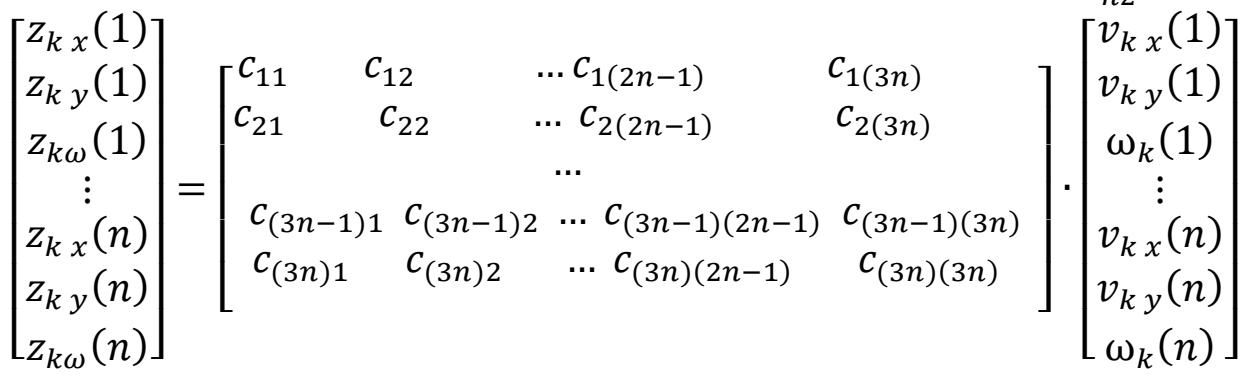

In (4) for convenience of writing, the "wavy line" icon above the matrix elements is omitted. Further, the matrices A, B, C and their elements will be denoted without a wavy line. Let us find the solution (1) without the second equation, which is the measuring part of the system. 
The quadratic functional of quality, which determines the energy of control and displacement, is expressed as follows

$$
I=\frac{1}{2} \int_{t_{0}}^{t_{f}}\left(x^{T} Q x+u^{T} G u\right) d t, Q \geq 0, G>0,
$$

where $\mathrm{Q}$ and $\mathrm{G}$ are positive arbitrarily defined matrices. The matrices $Q$ and $G$ are chosen arbitrarily.

It is not always possible to obtain a solution of the equation for finding $u$. It is proposed to select these matrices by selection or simulation modelling [19], [20].
The solution (1) for the quality criterion (5), minimizing the control and displacement energy, is determined by the following expression [19], [20].

$$
u=-G^{-1} B^{T} K x
$$

where $\mathrm{K}$ is the Cauchy matrix, $\mathrm{K}=\mathrm{K}^{\mathrm{T}}$, which can be found by solving the Riccati equation [19]

$$
\begin{array}{rl}
-\dot{K}=Q+A^{T} & K+K^{T} A \\
& -K^{T} B G^{-1} B^{T} K, \quad K\left(t_{f}\right)=0
\end{array}
$$

Cauchy Matrix

$$
K=\left[\begin{array}{ccccc}
k_{11} & k_{12} & \cdots & k_{1(n-1)} & k_{1 n} \\
k_{21} & k_{22} & \cdots & k_{2(n-1)} & k_{2 n} \\
\vdots & \vdots & \ddots & \vdots & \vdots \\
k_{(n-1) 1} & k_{(n-1) 2} & \cdots & k_{(n-1)(n-1)} & k_{(n-1) n} \\
k_{n 1} & k_{n 2} & \cdots & k_{n(n-1)} & k_{n}
\end{array}\right], k_{i j}=k_{j i}
$$

where $\boldsymbol{\zeta}_{\boldsymbol{n}}=\left[\varsigma_{1}, \varsigma_{2}, \ldots, \varsigma_{n}\right]^{\boldsymbol{T}}$ $\mathrm{Q}$ and $\mathrm{G}$ are used in the quadratic functional of quality (5), which is also positive.

Thus, the robot group is controlled by the solution (6) according to the model (4) with calculation of the matrices of state $A_{k}$ and the control matrix $B_{k}$ at each step $k$. The matrix $\mathrm{C}=\mathrm{C}_{\mathrm{k}}$ at each step $\mathrm{k}$ remains unchanged, determined by the information-measuring system, can be represented as

$$
C=\left[\begin{array}{cccc}
1+\varsigma_{1} & 0 & \cdots & 0 \\
0 & 1+\varsigma_{2} & \cdots & 0 \\
0 & 0 & \cdots & 1+\varsigma_{n}
\end{array}\right],(8)
$$

is a random vector that maps the random character of measurements to an information measuring system.

\section{Result and discussion}

Important properties of a complex system are its manageability and identifiability. Manageability allows in principle to implement the target function of the system. Identifiability in its parametric form will be used to diagnose the state of the system in terms of its potential functionality.

Controllability. For a linear stationary system, at each step of linearization, the criterion of controllability is the rank of the extended matrix:

$$
\operatorname{rank}\left[B_{k} \vdots A_{k} B_{k} \vdots\left(A_{k}\right)^{2} B_{k} \vdots \cdots \vdots\left(A_{k}\right)^{n-1} B_{k}\right]=n .
$$

If condition (9) is satisfied, then the system is controllable.

Identifiability. In abstract-theoretical analysis, identifiability is a particular case of observability. Identity is understood as the receipt or refinement of the model of a real object from experimental data. For a linear stationary system at each step of linearization, the criterion of identifiability and observability is the rank of the expanded matrix:

$$
\operatorname{rank}\left[C_{k}^{T} \vdots A_{k}^{T} C_{k}^{T} \vdots\left(A_{k}^{T}\right)^{2} C_{k}^{T} \vdots \cdots \vdots\left(A_{k}^{T}\right)^{n-1} C_{k}^{T}\right]=n
$$

If condition (9) and (10) are satisfied, then the system is observable, manageable and identifiable.

The model of a complex system consisting of a group of robots includes models of mechatronic devices. In the mechatronic device model, parameters such as inductance, coercive force of magnetic components, leakage currents, etc., which are changed during operation due to aging and interaction with other components of the system, are directly or indirectly connected. It is proposed to carry out diagnostics of drives, electronic control devices and software in a complex way based on the parametric model (4) and calculating the criterion of identifiability (10), 
taking into account the degree of proximity to zero of the main determinants in calculating the rank of the expanded matrices (9) and (10).
We write down the solution of the informationmeasuring problem of the model (4).

$$
\left[\begin{array}{c}
v_{k x}(1) \\
v_{k y}(1) \\
\omega_{k}(1) \\
\vdots \\
v_{k x}(n) \\
v_{k y}(n) \\
\omega_{k}(n)
\end{array}\right]=\left[\begin{array}{llllll}
c_{11} & c_{12} & \ldots & c_{1(2 n-1)} & \ldots & c_{1(3 n)} \\
c_{21} & c_{22} & \ldots & c_{2(2 n-1)} & \ldots & c_{2(3 n)} \\
& & \ldots & & & \\
c_{(3 n-1) 1} & c_{(3 n-1) 2} & \ldots & c_{(3 n-1)(2 n-1)} & \ldots & c_{(3 n-1)(3 n)} \\
c_{(3 n) 1} & c_{(3 n) 2} & \ldots & c_{(3 n)(2 n-1)} & \ldots & c_{(3 n)(3 n)}
\end{array}\right]^{-1} \cdot\left[\begin{array}{c}
z_{k x}(1) \\
z_{k y}(1) \\
z_{k \omega}(1) \\
\vdots \\
z_{k x}(n) \\
z_{k y}(n) \\
z_{k \omega}(n)
\end{array}\right]
$$

The vector of the right-hand side of (11) is substituted in (6) as an estimate of the state. A large inaccuracy in the measurement leads to a larger control error and, in the end, leads to a loss of controllability. Moreover, with the loss of identifiability, the determinant of the inverse matrix in (11) is close to zero and the measurement problem

\section{Conclusions}

In this paper we present:

Mathematical model of diagnostics of a complex system, based on the matrix model of control in the time domain.

Optimal discrete algorithm for computing the control vector for a group of mobile robots.

Algorithm for monitoring the system based on the potential for performing the objective function by determining the properties of the system-controllability, observability and identifiability, by calculating the rank of the matrix sequences composed of the matrices of state, control, and measurement.

Thus, for a complex system, from the measurements of the current state, the correspondence of its behaviour to the a priori model of this complex system is determined, which allows us to speak of the fulfilment of the objective function.

\section{Acknowledgement}

The reported study was funded by RFBR according to the research project № 18-08-00772 A.

\section{References}

[1] HRICOVÁ, R.: Situation on intermodal terminals in the slovak republic, Acta logistica, Vol. 4, No. 3, pp. 19-23, 2017. doi:10.22306/al.v4i3.51

[2] FERENCOVÁ, J., HURNÁ, S.: Logistics technologies in aviation, Acta logistica, Vol. 4, No. 2, pp. 11-17, 2017. doi:10.22306/al.v4i2.3

[3] STRAKA, M.: The position of distribution logistics in the logistic system of an enterprise, Acta logistica, Vol. 4, No. 2, pp. 23-26, 2017. doi:10.22306/al.v4i2.5 becomes poorly conditioned. Such approach will allow to perform complex diagnostics of the system and in time to detect potentially faulty components and to exclude them from the system.

[4] KOVÁCS, G.: Logistics and production processes today and tomorrow, Acta logistica, Vol. 3, No. 4, pp. 1-5, 2016. doi:10.22306/al.v3i4.71

[5] WITKOWSKI, K., HUK, K., PERZYŃSKA, A.: Selected it solutions in logistics strategies of supply chains, Acta logistica, Vol. 3, No. 4, pp. 31-37, 2016. doi:10.22306/al.v3i4.75

[6] BALLOVÁ, L.: Options of transport for kosice's surrounding in nonstandard times, Acta logistica, Vol. 3, No. 1, pp. 19-22, 2016. doi:10.22306/al.v3i1.55

[7] IGNÁCZOVÁ, K.: FMEA (failure mode and effects analysis) and proposal of risk minimizing in storage processes for automotive client, Acta logistica, Vol. 3, No. 1, pp. 15-18, 2016. doi:10.22306/al.v3i1.54

[8] FILKIN, N.M., ZYKOV, S.N., KORSHUNOV, A.I., ZAVIALOV, P.M., BOŽEK, P.: A unified machine for technological electric transport ladder-backbone loadbearing system, Acta logistica, Vol. 4, No. 3, pp. 5-8, 2017. doi:10.22306/al.v4i3.7

[9] RICHTARČÍK, F.: Usage of rfid technology for the needs of logistics of services, Acta logistica, Vol. 3, No. 1, pp. 5-8, 2016. doi:10.22306/al.v3i1.57

[10] BOŽEK P., FILKIN, N.M., ZYKOV, S.N., KORSHUNOV, A.I., ZAVIALOV, P.M.: A unified machine for technological electric transport loadbearing system, Acta logistica, Vol. 4, No. 2, pp. 1-5, 2017. doi:10.22306/al.v4i2.1

[11] TREFILOV, S.A., KALINKIN, A.A., NIKITIN, Y.R.: High-maneuverable transport robot, University Review, Vol. 1, No 2. Trencin, Alexander Dubcek University of Trencin, Slovakia, Izhevsk State Technical University, Russia. pp. 34-39, 2007.

[13] ABRAMOV, I.V., NIKITIN, YU.R., ABRAMOV, A.I., SOSNOVICH, E.V., BOŽEK, P.: Control and diagnostic model of brushless DC motor, Journal of Electrical Engineering, Vol. 65, No. 5, pp. 277- 282, 2014. 
[14] ABRAMOV, I., BOŽEK, P., NIKITIN, Yu., ABRAMOV, A., SOSNOVICH, E., STOLLMANN, V.: Diagnostics of electrical drives, Proceedings of International Conference on Electrical Drivers and Power Electronics EDPE 2015. 21-23.09.2015, Tatranska Lomnica, The High Tatras, Slovak Republic, pp. 364-367, 2015. Publisher IEEE, 345 E 47TH ST, NEW YORK, NY 10017 USA. Accession Number: WOS:000380458300062.

[15] NIKITIN, Yu., TURYGIN, Yu., SOSNOVICH, E., BOZEK, P.: Trends in Control of NC Machines, Procedia Engineering, Vol. 149, pp.352-358, 2016. doi: $10.1016 /$ j.proeng. 2016.06 .678

[16] HRUBOŠ, M., SVETLÍK, J., NIKITIN, Yu., PIRNÍK, R., NEMEC, D., ŠIMÁK, V., JANOTA, A., HRBČEK, J., GREGOR, M.: Searching for collisions between mobile robot and environment, International Journal of Advanced Robotic Systems, September-Octob., pp. 1-11, 2016. doi: $10.1177 / 1729881416667500$.

[17] TURYGIN, Yu., BOŽEK, P., NIKITIN, Yu., SOSNOVICH, E., ABRAMOV, A.: Enhancing the reliability of mobile robots control process via reverse validation, International Journal of Advanced Robotic Systems, November-December, pp. 1-8, 2016. doi: $10.1177 / 1729881416680521$.

[18] ABRAMOV, I., NIKITIN, Y., ZORINA, O., BOŽEK, P., STEPANOV, P., STOLLMANN, V.: Monitoring of technical condition of motors and bearings of woodworking equipment, Acta Facultatis Xylologiae, Vol. 56, No. 2, pp. 97-104, 2014.

[19] SAGE, E.P., WHITE, C.S.: Optimum control of systems: Trans. from the English / B.R. Levina. - M .: Radio and Communication,pp. 392, 1982. (Second ed.: USA, 1977) (Original in Russian)

[20] Krasovskogo, A.A.: A handbook on the theory of automatic control / A.A.Krasovskogo, M.: Science. Gl.red.phys.-math. lit., p. 712, 1987. (Original in Russian)

\section{Review process}

Single-blind peer review process. 